\title{
O gênero Merremia (Convolvulaceae) na Região Sul do Brasil ${ }^{1}$
}

\author{
The genus Merremia (Convolvulaceae) in Southern Brazil
}

Priscila Porto Alegre Ferreira ${ }^{2,4} \&$ Silvia Teresinha Sfoggia Miotto ${ }^{3}$

\begin{abstract}
Resumo
Merremia Dennst. ex Endl. compreende aproximadamente 60 espécies, amplamente distribuídas nos trópicos e subtrópicos de ambos os hemisférios. Das 14 espécies do gênero conhecidas para o Brasil, nove foram confirmadas para a Região Sul: M. cissoides (Lam.) Hallier f., M. digitata (Spreng.) Hallier f. var. digitata, M. digitata var. elongata (Choisy) D.F.Austin \& Staples, M. dissecta (Jacq.) Hallier f., M. hassleriana (Chodat) Hassl., M. macrocalyx (Ruiz \& Pav.) O’Donell, M. tomentosa (Choisy) Hallier f., M. tuberosa (L.) Rendle e M. umbellata (L.) Hallier f. São fornecidos chave de identificação, descrições morfológicas, dados de distribuição geográfica, hábitat e ilustrações dos táxons. Merremia hassleriana constitui uma nova ocorrência para o Paraná.
\end{abstract}

Palavras-chave: morfologia, Paraná, Rio Grande do Sul, Santa Catarina, taxonomia.

\begin{abstract}
Merremia Dennst. ex Endl. comprises about 60 species widely distributed in the tropics and subtropics of both hemispheres. Among the 14 species occurring in Brazil, nine were confirmed for the Southern region: M. cissoides (Lam.) Hallier f., M. digitata (Spreng.) Hallier f. var. digitata, M. digitata var. elongata (Choisy) D.F.Austin \& Staples, M. dissecta (Jacq.) Hallier f., M. hassleriana (Chodat) Hassl., M. macrocalyx (Ruiz \& Pav.) O'Donell, M. tomentosa (Choisy) Hallier f., M. tuberosa (L.) Rendle, and M. umbellata (L.) Hallier f. Analytical key, morphologic descriptions, geographical data, habitat and illustrations of the taxa of Merremia in Southern Brazil are provided. Merremia hassleriana is a new record for Paraná State.
\end{abstract}

Key words: morphology, Paraná, Rio Grande do Sul, Santa Catarina, taxonomy.

\section{Introdução}

Convolvulaceae compreende 55 gêneros e cerca de 1.930 espécies, amplamente distribuídas, sendo que a maior diversidade está concentrada em regiões tropicais e subtropicais (Judd et al. 2009). Trata-se de um grupo monofilético, dividido em duas subfamílias: Humbertioideae e Convolvuloideae (Stefanovic et al. 2002, 2003).

Merremia Dennst. ex Endl. pode ser reconhecido pelo conjunto de algumas características, como as anteras espiraladas após a antese, os grãos de pólen colpados com exina não espinhosa e o fruto do tipo cápsula 4-valvar. O gênero pertence ao grupo "Merremieae", juntamente com Aniseia Choisy (Américas),
Decalobanthus Ooststr. (Ásia), Hewittia Wight \& Arn. (África e Ásia), Hyalocystis Hallier f. (Ásia), Iseia O’Donell (Américas), Odonellia K.R. Robertson (Américas), Operculina Silva Manso (pantropical), Tetralocularia O’Donell (Américas) e Xenostegia D.F. Austin \& Staples (África, Ásia e Austrália) (Austin 1998).

Os principais estudos taxonômicos publicados com o gênero foram os de Rendle (1905), O’Donell (1939, 1941), Ferguson et al. (1977), Austin (1979), Austin \& Staples (1983), Demissew (2001) e Ferrer-Pereira et al. (2010).

Merremia possui aproximadamente $60-80$ espécies ocorrentes nos trópicos e subtrópicos de ambos os hemisférios (Austin 1982a). No Brasil, ocorrem 14 espécies (Simão-Bianchini

\footnotetext{
${ }^{1}$ Parte da tese de Doutorado da primeira autora.

${ }^{2}$ Universidade Federal do Rio Grande do Sul, Programa de Pós-graduação em Botânica, Av. Bento Gonçalves 9500, bl. IV, Prédio 43433, Campus do Vale, 91501-970, Porto Alegre, RS, Brasil.

${ }^{3}$ Universidade Federal do Rio Grande do Sul, Depto. Botânica, Av. Bento Gonçalves 9500, bl. IV, Prédio 43433, Campus do Vale, $91501-970$, Porto Alegre, RS, Brasil.

${ }^{4}$ Autor para correspondência: priscila.poaf@hotmail.com
} 
\& Ferreira 2012) nos mais variados ambientes, sendo muito frequentes em bordas de florestas, em formações campestres, no cerrado e em áreas alteradas. Lorenzi (1982), Kissmann \& Groth (1992) e Lorenzi \& de Souza (1999) ressaltaram a importância de espécies de Merremia como ornamentais e/ou invasoras de culturas.

No Brasil, os estudos direcionados ao gênero foram o de Falcão (1954), que constituiu-se em uma compilação do trabalho de O'Donell (1941), e o de Leite et al. (2005) que abordaram a morfologia polínica das espécies ocorrentes no estado da Bahia. Para a Região Sul, houve apenas contribuições ao estudo de Convolvulaceae em geral, como o trabalho de Rambo (1962), que lista os espécimes depositados no herbário PACA, e os de Falcão $(1973,1976)$ que apresentaram sucintas descrições morfológicas baseadas no material disponível no herbário RB.

Este estudo teve como objetivo o levantamento florístico do gênero Merremia nos três estados da Região Sul do Brasil (Paraná, Santa Catarina e Rio Grande do Sul). São fornecidos chave analítica, descrições morfológicas, ilustrações, dados sobre distribuição geográfica, hábitat, floração e frutificação dos táxons.

\section{Material e Métodos}

O estudo baseou-se em revisão bibliográfica e de herbários, coletas e observações no campo, além de estudo morfológico.

Foram revisados os seguintes herbários (acrônimos de acordo com Thiers 2012): CRI, CTES, ESA, FLOR, FUEL, FURB, HAS, HBR, HCF, ICN, INPA, LIL, LP, MBM, MVFA, MVM, NY, PACA, PEL, R, RB, S, SI, SP, SPF, UB, UEC, UPCB e HUCS (Universidade de Caxias do Sul, cuja sigla não é oficial), através de empréstimos, visitas ou envio de fotografias das exsicatas, totalizando 1.167 espécimes analisados.

Foram realizadas 41 excursões aos três Estados da Região Sul para coleta e observação dos táxons, no período de quatro anos, totalizando 160 dias no campo. O material coletado encontra-se depositado no Herbário do Instituto de Biociências da Universidade Federal do Rio Grande do Sul (ICN), Porto Alegre, RS.

Os basiônimos estão de acordo com as revisões taxonômicas de O'Donell (1941) e Austin \& Staples (1983).

Buscou-se utilizar no mínimo dez exsicatas de cada espécie para as descrições morfológicas e, na falta de material da Região Sul, foram analisados exemplares de outras localidades. A terminologia utilizada seguiu Gonçalves \& Lorenzi (2011) para hábito, Radford et al. (1974) para forma, base, ápice e margem das estruturas, Payne (1978) para indumento e Font Quer (1979) para inflorescências. As medidas das estruturas vegetativas e reprodutivas representam valores extremos encontrados entre os indivíduos analisados.

As ilustrações dos hábitos e das folhas foram elaboradas a partir de material herborizado e os detalhes de indumento, flores e frutos foram realizados com auxílio de câmara-clara acoplada a microscópio estereoscópico.

A citação dos ambientes de ocorrência das espécies está de acordo com Iganci et al. (2011).

\section{Resultados e Discussão}

Tratamento taxonômico

Merremia Dennst. ex Endl., Gen. Pl. 1: 1403. 1841. Espécie-tipo: Merremia hederacea (Burm. f.) Hallier f., Bot. Jahrb. Syst. 18: 118. 1893.

Trepadeiras, arbustos, subarbustos ou ervas; ramos volúveis, prostrados ou eretos, glabros ou com tricomas simples, estrelados e/ou glandulares. Lâminas foliares inteiras a palmatissectas ou compostas, com 3-7 folíolos. Flores pentâmeras, em dicásios. Brácteas e bractéolas lineares a ovadas. Sépalas subiguais a desiguais. Corola campanulada a infundibuliforme, branca ou amarela, raro rosa ou alaranjada, interior do tubo mais escuro ou vináceo a purpureo; áreas mesopétalas glabras ou pilosas. Estames inclusos, geralmente em tamanhos desiguais; filetes com tricomas glandulares na base, esparso a denso-pubescentes; anteras espiraladas após a antese; pólen 3-12 colpado, com ornamentação da exina granulada. Ovário globoso a cônico, glabro, 2 (-4) locular, (1-)2 rudimentos seminais por lóculo; disco hipógino presente; estigma 2-globoso. Cápsula 4-valvar. Sementes glabras a tomentosas.

Nove táxons do gênero Merremia foram confirmados para a Região Sul: M. cissoides (Lam.) Hallier f., M. digitata (Spreng.) Hallier f. var. digitata, M. digitata var. elongata (Choisy) D.F.Austin \& Staples, M. dissecta (Jacq.) Hallier f., M. hassleriana (Chodat) Hassl., M. macrocalyx (Ruiz \& Pav.) O'Donell, M. tomentosa (Choisy) Hallier f., M. tuberosa (L.) Rendle e M. umbellata (L.) Hallier f. Merremia hassleriana constitui uma nova ocorrência para o Paraná. 


\section{Chave para as espécies de Merremia na Região Sul do Brasil}

1. Folhas simples com lâminas inteiras a lobadas

2. Subarbustos eretos ou prostrados com ápices volúveis, tricomas estrelados, dicásios com 1-5 flores, corola branca

3. Subarbustos eretos, corola com $2-2,5 \mathrm{~cm}$ de comprimento

7. M. tomentosa

3'. Subarbustos prostrados com ápices volúveis, corola com 3-4,5 cm de comprimento

4. Ramos e lâminas foliares tomentosos 3. M. digitata var. elongata

4'. Ramos e lâminas foliares hirsutos 5. M. hassleriana

2'. Trepadeiras, tricomas simples, dicásios umbeliformes com 1-15 flores, corola amarela 9. M. umbellata

1'. Folhas compostas ou simples com lâminas palmatissectas

5. Folhas compostas, 3-5-folioladas

6. Tricomas estrelados 2. M. digitata var. digitata

6'. Tricomas simples e/ou glandulares

7. Folíolos glabros ou esparso-pilosos, tricomas simples, sépalas externas glabras

7'. Folíolos e sépalas externas pubescentes, tricomas glandulares e simples 6. M. macrocalyx 1. M. cissoides

5'. Folhas simples palmatissectas, lâminas com 3-9 segmentos

8. Ramos e lâminas foliares tomentosos 3. M. digitata var. elongata

8'. Ramos e lâminas foliares glabros ou hirsutos

9. Corola branca, sementes glabras

4. M. dissecta

9'. Corola amarela, sementes pubescentes 8. M. tuberosa

1. Merremia cissoides (Lam.) Hallier f., Bot. Jahrb. Syst. 16: 552. 1893. Convolvulus cissoides Lam., Tabl. Encycl. 1: 462. 1791.

Fig. 1a-f

Trepadeira; ramos pubescentes (tricomas glandulares) e esparso-hirsutos (tricomas simples). Folhas 5-folioladas; pecíolo e peciólulos com indumento semelhante ao dos ramos, $0,5-3 \mathrm{~cm}$ compr. e $0,1-0,5 \mathrm{~cm}$ compr., respectivamente; folíolos esparso-pubescentes em ambas as faces, com tricomas glandulares mais concentrados nas margens e sobre as nervuras da face abaxial, 2,5-4,5 × 0,8-2 cm, elípticos, inteiros, base atenuada, margem denteada ou serreada, raro lisa, ápice agudo. Dicásios com 1-7 flores. Pedúnculo e pedicelos com indumento semelhante ao dos ramos, $1-4 \mathrm{~cm}$ compr. e $0,2-1 \mathrm{~cm}$ compr., respectivamente. Brácteas e bractéolas lineares, 0,3-2 cm compr., pubescentes (tricomas glandulares) e esparsohirsutas (tricomas simples). Sépalas caudadas, externas ovadas a truladas, $1,3-1,8 \times 0,4-0,6 \mathrm{~cm}$, com indumento semelhante ao das brácteas, internas lanceoladas, $1,3-1,8 \times 0,2-0,4 \mathrm{~cm}$, pubescentes na região central (tricomas glandulares), com margem hialina. Corola campanulado-infundibuliforme, totalmente branca ou com o interior do tubo vináceo, 1,5-2,5 cm compr., glabra. Estames 0,7$1,3 \mathrm{~cm}$ compr., filetes esparso-pubescentes. Ovário subgloboso, 4-locular, um rudimento seminal por lóculo; estilete 1,3-1,6 cm compr. Cápsula globosa, 4-valvar, com 3-4 sementes pretas, $0,4-0,5 \mathrm{~cm}$ compr., esparso-pubescentes.

Material selecionado: PARANÁ: Foz do Iguaçu, 8.VIII.1947, fl., G. Stellfeld 1251(MBM). Terra Rica, 13.I.2012, fl. e fr., P.P.A. Ferreira et al. 831 (ICN). RIO GRANDE DO SUL: Montenegro, 20.VII.1954, fr., $B$. Rambo 41424 (PACA). Sapucaia do Sul, 4.IV.1935, fr., B. Rambo 2044 (PACA).

Material adicional selecionado: BRASIL. PARÁ: Porto Trombetas, 1991, fl. e fr., Evandro \& Knowles 410 (INPA).

Distribui-se desde o México até a Argentina (O’Donell 1941), no Brasil está registrada para todos os estados, exceto Santa Catarina (SimãoBianchini \& Ferreira 2012). Ocorre em bordas de Floresta Estacional e em ambientes ruderais. Floresce e frutifica o ano todo.

Merremia cissoides pode ser reconhecida pelo indumento constituído de tricomas simples e glandulares nos órgãos vegetativos e reprodutivos, semelhante apenas à Merremia digitata var. ericoides (Meisn.) D.F. Austin \& Staples, que possui folhas sésseis ou curto-pecioladas (até 0,5 $\mathrm{cm}$ de comprimento) e folíolos lineares, ocorrente em Savana Tropical das Regiões Norte, Nordeste, Centro-Oeste e Sudeste. 

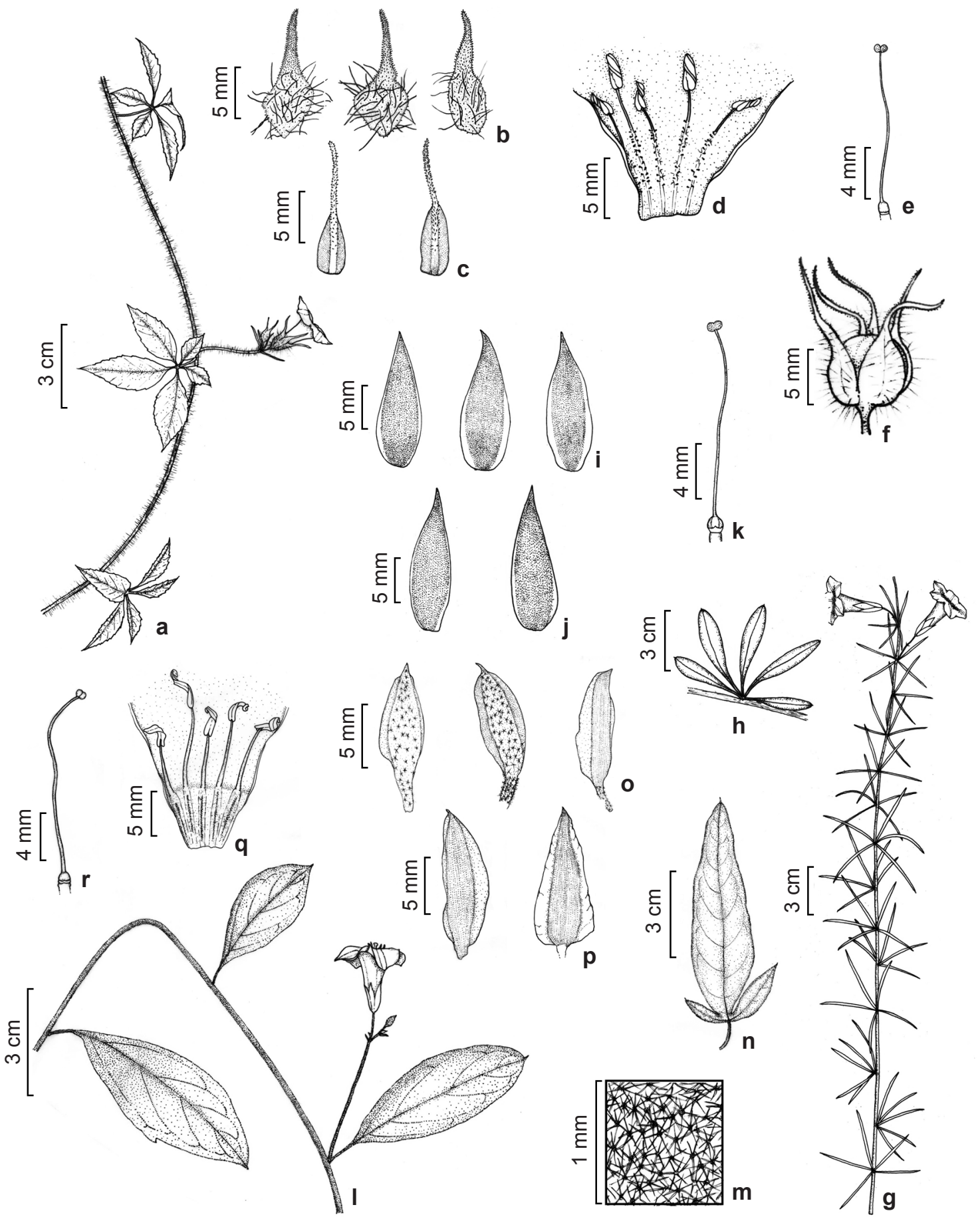

Figure 1 - a-f. Merremia cissoides (Lam.) Hallier - a. ramo (Evandro \& Knowles 410). b. sépalas externas. c. sépalas internas. d. corola aberta mostrando o androceu. e. gineceu. f. fruto (Ferreira et al. 831). g-k. Merremia digitata var. digitata (Spreng.) Hallier f. - g. ramo (J.C. Lindeman \& J. Haas 5619). h. folha (Barros 2564). i. sépalas externas. j. sépalas internas. k. gineceu (Medeiros 8). 1-r. Merremia digitata var. elongata (Choisy) D.F.Austin \& Staples - 1. ramo. m. indumento da face abaxial da folha. $n$. folha. o. sépalas externas. p. sépalas internas. q. corola aberta mostrando o androceu. r. gineceu (Ferreira et al. 636).

Figure 1 - a-f. Merremia cissoides (Lam.) Hallier f. - a. stem (Evandro \& Knowles 410). b. outer sepals. c. inner sepals. d. corolla, opened to show androecium. e. gynoecium. f. fruit (Ferreira et al. 831). g-k. Merremia digitata var. digitata (Spreng.) Hallier f.-g. stem (J.C. Lindeman \& J. Haas 5619). h. leaf(Barros 2564). i. outer sepals. j. inner sepals. k. gynoecium (Medeiros 8). 1-r. Merremia digitata var. elongata (Choisy)D.F.Austin \& Staples-1. stem. m. trichomes on abaxial surface of leaf,. n. leaf. o. outer sepals. p. inner sepals. q. corolla, opened to show androecium. r. gynoecium (Ferreira et al. 636). 
2. Merremia digitata (Spreng.) Hallier f. var. digitata, Bot. Jahrb. Syst. 16: 552. 1893. Gerardia digitata Spreng., Syst. Veg. 16(2): 808. 1825.

Fig. 1g-k

Subarbusto prostrado com ápices volúveis; ramos tomentosos, glabrescentes, tricomas estrelados. Folhas (3-)5-folioladas; pecíolo e peciólulos $0-0,2 \mathrm{~cm}$ compr., esparso-pilosos, glabrescentes; folíolos esparso-pilosos em ambas as faces, glabrescentes, $1-5 \times 0,1-0,5 \mathrm{~cm}$, lineares, elípticos, espatulados, oblanceolados ou lanceolados, inteiros, base cuneada, margem lisa, ápice agudo ou obtuso. Dicásios com 1-2 flores. Pedúnculo e pedicelos esparso-pilosos, 1-5 cm compr. Brácteas e bractéolas lineares ou lanceoladas, esparsopilosas a glabras, $0,1-0,3 \mathrm{~cm}$ compr. Sépalas ovadas, glabras, com margem hialina, ápice agudo a acuminado, mucronado, externas $1-1,2 \times$ $0,3-0,4 \mathrm{~cm}$, internas $1,4-1,5 \times 0,3-0,4 \mathrm{~cm}$. Corola campanulado-infundibuliforme, branca, $2,5-3,5 \mathrm{~cm}$ compr., glabra. Estames 1-1,4 cm compr., filetes esparso pubescentes. Ovário globoso, 4-locular, um rudimento seminal por lóculo; estilete 1,6-1,9 cm compr. Cápsula globosa, 4-valvar, com 3-4 sementes pretas, 0,3-0,5 cm compr., esparso-vilosas.

Material selecionado: PARANÁ: São Jerônimo da Serra, 24.III.1988, fr., Silveira et al. (FUEL 5357); 4.III.1982, fl., J.C. Lindeman \& J.H. Haas 5619 (RB).

Material adicional selecionado: BRASIL. SÃO PAULO: Itirapina, 3.II.1993, fl., F. Barros 2564 (SP); Pirassununga, 12.XII.1987, fl., J.D. Medeiros 8 (FLOR).

Ocorre na Guiana e no Brasil (O’Donell 1941), nos estados da Bahia, Minas Gerais, Goiás, Distrito Federal, Mato Grosso, Mato Grosso do Sul, São Paulo e Paraná (Simão-Bianchini \& Ferreira 2012), na Floresta Ombrófila Mista em campos arbustivos e rupestres. Floresce de novembro a junho e frutifica de março a junho.

Dentre as espécies brasileiras, assemelha-se à Merremia flagellaris (Choisy) O'Donell, mas esta difere por possuir indumento constituído de tricomas glandulares e folhas (5-)7-9-folioladas, ocorrente nas Regiões Centro-Oeste, Nordeste e Sudeste.

\section{Merremia digitata var. elongata (Choisy)}

D.F.Austin \& Staples, J. Arnold Arbor. 64(3): 484. 1983. Batatas tomentosa var. elongata Choisy, Prodr. [A.P. de Candolle] 9: 337. 1845. Fig. 11-r

Subarbusto prostrado com ápices volúveis; ramos tomentosos, tricomas estrelados. Pecíolo tomentoso, 0,2-1 cm compr.; lâminas foliares tomentosas em ambas as faces, inteiras ou palmatissectas com 3,5(-7) segmentos, elípticas, oblongas ou lanceoladas, $3-7(-10,5) \times 0,8-4 \mathrm{~cm}$, base obtusa, margem lisa, ápice agudo ou obtuso. Dicásios com 1-5 flores. Pedúnculo tomentoso, (0,5-)1-2(-5) $\mathrm{cm}$ compr., pedicelos esparso-pubescentes, $0,5-2 \mathrm{~cm}$ compr. Brácteas e bractéolas lanceoladas, esparsopubescentes, 0,1-0,2 cm compr. Sépalas ovadas ou oblongas, com margem hialina, ápice agudo ou obtuso, mucronado, externas $0,9-1 \times 0,4 \mathrm{~cm}$, glabras ou esparso-pubescentes, internas $1-1,3 \times 0,4-0,6$ $\mathrm{cm}$, glabras. Corola campanulado-infundibuliforme, branca, 3-4 cm compr., glabra. Estames 1,5-2 $\mathrm{cm}$ compr., filetes esparso pubescentes. Ovário subgloboso, 4-locular, um rudimento seminal por lóculo; estilete 2-2,5 cm compr. Cápsula subglobosa, sementes maduras não vistas.

Material selecionado: PARANÁ: Arapoti, 6.IV.1970, fl., G. Hatschbach 24108 (NY). Jaguariaíva, 3.III.1966, fl., G. Hatschbach \& G.H. Haas 13971 (NY); 11.X.1999, fl., L. von Linsingen 222 (SP); 24.I.2000, fl., L. von Linsingen 576 (SP); 24.V.2003, fl., A.C. Cervi et al. 8410 (UPCB); 3.II.2011, fl., P.P.A. Ferreira et al. 642 (ICN); 3.II.2011, fl., P.P.A. Ferreira et al. 636 (ICN); 4.II.2011, fl., P.P.A. Ferreira et al. 645 (ICN); 18.II.1987, fl. e fr., G. Hatschbach 50889 (NY, INPA, SP); 5.XI.1928, fl., F.C. Hoehne 23401 (SP); 8.XII.1910, fl., P. Dusén 11012 (S). Sengés, 19.I.1965, fl., L.B. Smith et al. 14837 (HBR); 16.XII.2010, fl., J.R.V. Iganciet al. 748 (ICN).

Endêmica do Brasil, nos estados de Minas Gerais, São Paulo, Goiás, Distrito Federal e Paraná (Simão-Bianchini \& Ferreira 2012), onde é comum nos campos do remanescente de Savana Tropical, ocorrente entre os municípios de Jaguariaíva e Sengés.

Pode ser reconhecida por ser prostrada com ápices volúveis, as folhas podem ser desde inteiras até 5 (raro 7) folioladas e denso tomentosas, com tricomas estrelados. Assemelha-se à M. tomentosa, que possui o mesmo indumento, mas trata-se de um subarbusto ereto com folhas geralmente oblongas e sempre inteiras.

Citada para o Paraná por O’Donell (1941) como Merremia contorquens (Choisy) Hallier f., a qual foi incluída como sinônimo de $M$. digitata var. elongata por Austin \& Staples (1983). No entanto, Merremia contorquens é uma espécie válida, endêmica de Minas Gerais.

4. Merremia dissecta (Jacq.) Hallier f., Bot. Jahrb. Syst. 16: 552. 1893. Convolvulus dissectus Jacq., Observ. Bot. 2: $4.1767 . \quad$ Fig. 2a-g

Trepadeira; ramos glabros a hirsutos, tricomas simples. Pecíolo glabro a hirsuto, 1,5-10 cm compr.; lâminas foliares glabras a hirsutas em ambas as faces, palmatissectas com 5-9 segmentos, 
contorno ovado a suborbicular, 4-12 × 5-14 cm, segmentos oblongos, elípticos ou lanceolados, inteiros, lobados ou irregularmente partidos, ápice agudo a acuminado, às vezes obtuso. Dicásios com 1-7 flores. Pedúnculo e pedicelos glabros a hirsutos, 3-14 cm compr. e 2-4 cm compr., respectivamente. Brácteas e bractéolas lanceoladas, glabras a hirsutas, 0,2-0,6 cm compr. Sépalas ovadas, elípticas ou oblongas, ápice agudo ou obtuso, mucronado, externas $2-2,5 \times 0,8-1 \mathrm{~cm}$, glabras a hirsutas, internas 1,8-2,2 × 0,8-1 cm, glabras, com margem hialina na base. Corola campanulado-infundibuliforme, branca, 3-4,8 cm compr., glabra. Estames 1,5-2 cm compr., filetes denso-pubescentes. Ovário globoso, 2-locular, dois rudimentos seminais por lóculo; estilete 1,7-2,5 $\mathrm{cm}$ compr. Cápsula subglobosa, 4-valvar, cálice ampliado, com 2-4 sementes pretas, 0,7-0,8 cm compr., glabras.

Material selecionado: PARANÁ: Caiobá, 20.IV.1985, fr., Shirata \& Cunha (UPCB 13325). Campo Largo, 1.II.2011, fl., P.P.A. Ferreira et al. 619 (ICN). Campo Mourão, 11.I.2008, fl., M.G. Caxambu 2006 (HCF, MBM). Foz do Iguaçu, 20.III.2011, fl., P.P.A. Ferreira \& J. Durigon 746 (ICN). Guaíra, 9.XII.1956, fl., G. Hashimoto 20742 (SP). Guaraqueçaba, 21.XII.2011, fl., P.P.A. Ferreira et al. 809 (ICN). Ibiporã, 16.X.1986, fl., S.C. Gouveia (FUEL 3900). Ivaté, 12.I.2012, fl., P.P.A. Ferreira et al. 829 (ICN). Londrina, 31.III.1974, fl., $R$. Kummrow 543 (MBM). Paranaguá, 15.XII.1909, fl., P. Dusén 9001 (NY, S). SANTA CATARINA: Águas Mornas, 26.II.2011, fl., P.P.A. Ferreira et al. 687 (ICN); Angelina, 19.II.2010, fl., A. Stival-Santos et al. 1867 (FLOR). Brusque, 6.IV.1948, fl. e fr., R. Reitz 2992 (HBR, NY). Criciúma, 24.II.2011, fl., P.P.A. Ferreira et al. 670 (ICN). Dionísio Cerqueira, 18.III.2011, fl., P.P.A. Ferreira \& J. Durigon 726 (ICN). Florianópolis, I.2000, fl., R. Simão-Bianchini 1367 (SPF, SP, NY). Grão-Pará, 9.XI.2010, fl., P.P.A. Ferreira et al. 425 (ICN). Ibirama, 13.IV.1956, fl., R. Reitz \& M. Klein 3127 (HBR, NY). Indaial, 1.V.2006, fr., J.M. Kalk 57 (FURB). Laguna, 27.II.2011, fl., P.P.A. Ferreira 701 (ICN). Palhoça, 2.IV.1953, fr., M. Klein 465 (HBR). Praia Grande, 25.III.2005, fl. e fr., F. Marchett 162 (HUCS, MBM); São João Batista, 26.II.2011, fl., P.P.A. Ferreira et al. 694 (ICN). Siderópolis, 14.I.1982, fl., V.C. Zanette \& S. Caznok 525 (CRI). RIO GRANDE DO SUL: Alecrim, 8.I.2011, fl., P.P.A. Ferreira \& J. Durigon 605 (ICN). Arroio dos Ratos, 14.I.1985, fl., D.B. Falkenberg 2126 (FLOR). Boa Vista das Missões, 8.II.2010, fl., P.P.A. Ferreira 358 (ICN). Caçapava do Sul, 30.VIII.1977, fr., I. Ungaretti 547 (HAS). Capão da Canoa, 18.XII.2007, fl., P.P.A. Ferreira 127 (ICN). Caxias do Sul, 22.II.1999, fl., A. Kegler 207 (HUCS). Cristal, 11.I.2010, fl., P.P.A. Ferreira et al. 313 (ICN). Estrela, 22.I.1964, fl., E.
Pereira 8532 (PEL, LP). Giruá, 15.III.1965, fr., $K$. Hagelund 3370 (ICN). Iraí, 18.III.1964, fl. e fr., Brescia \& Borsani 3320 (MVFA). Lajeado, 3.III.1976, fl., K. Hagelund 10134 (ICN). Montenegro, 28.XII.1949, fl., A. Sehnem 4467 (PACA). Nonoai, III.1945, fl., B. Rambo 28207 (PACA). Pelotas, 16.III.1955, fl. e fr., J.C. Sacco 298 (FUEL, HAS, HBR, NY, PEL, PACA). Porto Alegre, 5.V.2004, fr., M. Grings 156 (ICN). Porto Xavier, 7.I.2011, fl., P.P.A. Ferreira \& J. Durigon 597 (ICN). Santa Cruz do Sul, 10.III.2008, fl., P.P.A. Ferreira 242 (ICN). Santa Maria, 20.I.1956, fl., O. Camargo 69 (PACA). Santo Antônio da Patrulha, 27.I.2010, fl., P.P.A. Ferreira \& G.A. Dettke 352 (ICN). Santo Antônio das Missões, 24.III.2010, fl., P.P.A. Ferreira et al. 395 (ICN). São Lourenço do Sul, 17.II.2008, fl., P.P.A. Ferreira 212 (ICN). Sarandi, 10.II.2010, fl., P.P.A. Ferreira 366 (ICN). Taquara, 7.III.2008, fl., P.P.A. Ferreira 231 (ICN).Tenente Portela, 4.VII.1986, fr., M. Bassan 442 (HAS).Torres, 16.I.1987, fl. e fr., N. Silveira 4191 (HAS). Três Coroas, 21.XI.2007, fl., P.P.A. Ferreira 70 (ICN).

A espécie distribui-se dos Estados Unidos à Argentina (O’Donell 1941). No Brasil não está registrada nos estados do Acre, Roraima, Amapá, Maranhão, Piauí, Ceará, Rio Grande do Norte e Paraíba (Simão-Bianchini \& Ferreira 2012). Ocorre na Floresta Ombrófila Densa, Floresta Ombrófila Mista, Floresta Estacional, Campos de Altitude Subtropicais, Restinga Subtropical/Temperada e Savana Subtropical/Temperada, muito comum em bordas de matas, campos abertos, campos arbustivos e em ambientes ruderais. Floresce e frutifica o ano todo, mais intensamente durante o verão.

Semelhante vegetativamente à Merremia macrocalyx, que difere por possuir folhas compostas e à $M$. tuberosa, que possui flores amarelas, sementes pubescentes e é sempre glabra.

O’Donell (1941) reconheceu Merremia dissecta var. edentata (Meisn.) O’Donell como sendo o táxon ocorrente no Brasil, baseado em características como: margem e indumento das lâminas foliares, dimensões e indumento das sépalas. Porém, após o exame detalhado de vasto material da espécie, inclusive no campo, observou-se que estas características são extremamente variáveis, sendo possível identificar os extremos das variedades de O'Donell. No entanto, foram encontrados indivíduos com características intermediárias, ou seja, com segmentos das lâminas foliares lisos e sépalas hirsutas ou glabras; com segmentos das lâminas foliares lobados a irregularmente partidos e sépalas, também, hirsutas ou glabras, assim como 

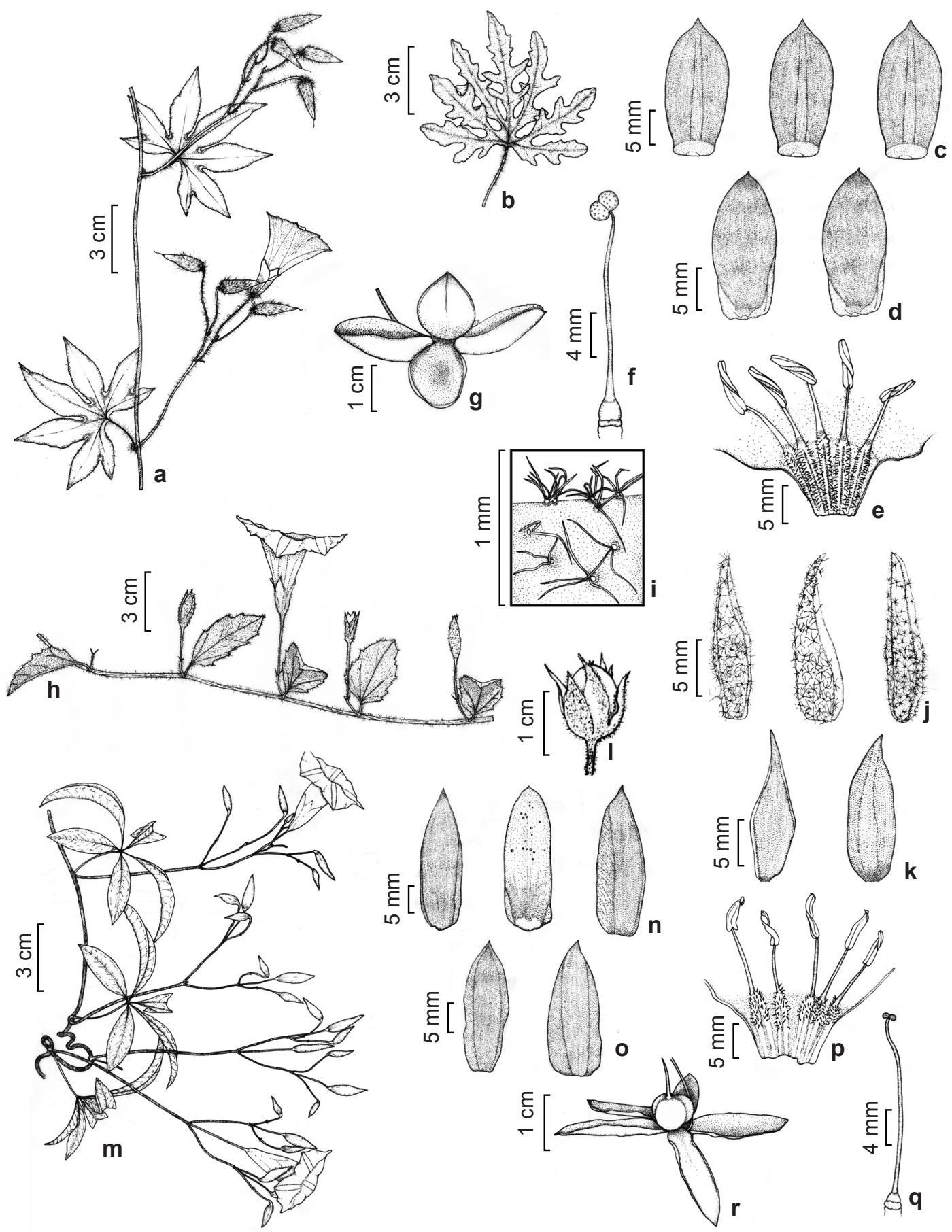

Figura 2 - a-g. Merremia dissecta (Jacq.) Hallier f. - a. ramo (Ferreira et al. 395). b. folha (Hagelund 3370). c. sépalas externas. d. sépalas internas. e. corola aberta mostrando o androceu. f. gineceu. g. fruto (Ferreira 70). h-1. Merremia hassleriana (Chodat) Hassl. - h. ramo. i. indumento da face adaxial da folha. j. sépalas externas. k. sépalas internas (Bianek 116). 1. fruto (Schinini et al. 28219). m-r. Merremia macrocalyx (Ruiz \& Pav.)O’Donell-m. ramo (Reitz \& Klein 6593). n. sépalas externas. o. sépalas internas. p. corola aberta mostrando o androceu. q. gineceu. r. fruto (Ferreira \& Durigon 736).

Figure 2 - a-g. Merremia dissecta (Jacq.) Hallier f. - a. stem (Ferreira et al. 395). b. leaf (Hagelund 3370). c. outer sepals. d. inner sepals. e. corolla, opened to show androecium. f. gynoecium. g. fruit (Ferreira 70). h-1. Merremia hassleriana (Chodat) Hassl. - h. stem. i. trichomes on adaxial surface of leaf. j. outer sepals. k. inner sepals (Bianek 116). 1. fruit (Schinini et al. 28219). m-r. Merremia macrocalyx (Ruiz \& Pav.) O'Donell - m. stem (Reitz \& Klein 6593). n. outer sepals. o. inner sepals. p. corolla, opened to show androecium. q. gynoecium. r. fruit (Ferreira \& Durigon 736). 
indivíduos com segmentos das lâminas foliares inteiros a lobados no mesmo ramo. Pela amplitude de variação encontrada, às vezes, no mesmo indivíduo, não foi possível enquadrar todos os espécimes examinados em variedades. Portanto, no presente estudo, não estão sendo consideradas as variedades e o material examinado foi tratado apenas ao nível de espécie.

5. Merremia hassleriana (Chodat) Hassl., Repert. Spec. Nov. Regni Veg. 9: 151. 1911. Ipomoea hassleriana Chodat, Bull. Herb. Boisser 2: 693. 1905.

Fig. 2h-1

Subarbusto prostrado com ápices volúveis; ramos hirsutos, tricomas estrelados. Pecíolo hirsuto, 0,4-1,2 cm compr.; lâminas foliares esparso-hirsutas em ambas as faces, inteiras ou trilobadas, ovadas, elípticas ou oblongas, 2,5-5 × $1,5-4 \mathrm{~cm}$, base aguda, truncada ou oblíqua, margem irregularmente denteada ou lisa, ápice agudo ou obtuso. Inflorescência uniflora. Pedúnculo hirsuto, 1-1,5 cm compr., pedicelo hirsuto, engrossado no ápice, 2-6 cm compr. Bractéolas lineares, hirsutas, 0,4-0,7 cm compr. Sépalas lanceoladas, ápice agudo ou acuminado, com margem hialina, externas hirsutas, $1-1,8 \times 0,3-0,5 \mathrm{~cm}$, internas glabras, $1,5-1,7 \times 0,4-0,5 \mathrm{~cm}$. Corola campanuladoinfundibuliforme, branca ou rosa, 4-4,5 cm compr., glabra. Estames 1,5-2,3 cm compr., filetes esparsopubescentes. Ovário cônico, 4-locular, um rudimento seminal por lóculo; estilete 1,8-2,5 cm compr. Cápsula subglobosa, 4-valvar, com 2-4 sementes castanho-escuras, 0,5-0,7 cm compr., vilosas.

Material selecionado: PARANÁ: Campo Mourão, 21.X.2004, fl. e fr., M.G. Caxambu 564 (HCF); 11.XI.2003, fl., A.E. Bianek 116 (MBM, HCF); 14.X.1965, fl., G. Hatschbach 12986(MBM); 9.XII.1960, fl., G. Hatschbach 7629 (MBM). Palmeira, 7.XI.2004, fl., M.G. Caxambu 699 (HCF).

Material adicional selecionado: PARAGUAI. ALTO PARANÁ: Hernandarias, 28.III.1993, fl. e fr., A. Schinini et al. 28219 (MBM, CTES, SI).

Espécie rara em toda sua área de distribuição, ocorrente no Paraguai, na Argentina (O’Donell 1941) e no Brasil, nos estados de Goiás, Mato Grosso do Sul e São Paulo (Simão-Bianchini \& Ferreira 2012), sendo aqui citada, pela primeira vez para o Paraná, em campos da Savana Tropical. Floresce e frutifica de outubro a abril.

Facilmente reconhecida pelo hábito prostrado com ápices volúveis, folhas com margem irregularmente denteada e pelo indumento hirsuto, constituído de tricomas estrelados, esparsos.
6. Merremia macrocalyx (Ruiz \& Pav.) O'Donell, Lilloa 6: 506. 1941. Convolvulus macrocalyx Ruiz \& Pav., Fl. Peruv. 2: 10, t. 118, f. b. 1799.

Fig. 2 m-r

Trepadeira; ramos glabros ou esparsopilosos, tricomas simples, raro glandulares. Folhas 5-folioladas; pecíolo e peciólulos glabros ou esparsopilosos, 2-6(-9) cm compr. e 0,1-0,7 cm compr., respectivamente; folíolos glabros ou esparsopilosos em ambas as faces, 3,5-9(-12) × 1,5-4,5 $\mathrm{cm}$, elípticos, inteiros, base cuneada, margem lisa ou ondulada, ápice acuminado. Dicásios com 2-15(-30) flores. Pedúnculo e pedicelos glabros ou esparso-pilosos, 3-8(-12) cm compr. e $1-4 \mathrm{~cm}$ compr., respectivamente. Brácteas e bractéolas lanceoladas, glabras, 0,1-0,2 cm compr. Sépalas ovadas ou oblongas, glabras, ápice agudo ou obtuso, mucronado, com margem hialina, externas 1,8-2,5 $\times 0,8-1 \mathrm{~cm}$, internas 2,3-2,9 × 0,9-1,1 cm. Corola campanulado-infundibuliforme, branca, 3,5-6 cm compr., glabra. Estames 1,8-2,3 cm compr., filetes denso-pubescentes. Ovário subgloboso, 4-locular, um rudimento seminal por lóculo; estilete $2-2,6 \mathrm{~cm}$ compr. Cápsula globosa, 4-valvar, cálice ampliado, com 3-4 sementes pretas, 0,4-0,6 cm compr., finamente pubescentes.

Material selecionado: PARANÁ: Adrianópolis, 5.IV.1976, fl., G. Hatschbach 38553 (SI). Amaporã, 27.IV.1988, fl., W.M. Kranz 265 (FUEL). Bocaiúva do Sul, 26.V.1953, fl., G. Hatschbach 3184 (UPCB).Campo Largo, 31.III.1957, fl. e fr., G. Hatschbach 3672 (HBR, MBM). Campo Mourão, 23.IV.2005, fr., E.M. Benjamim (HCF 2574). Cascavel, 24.XI.2011, fl., P.P.A. Ferreira et al. 785 (ICN). Cianorte, 20.V.1972, fl., G. Hatschbach 26679 (UPCB, MBM). Cornélio Procópio, 7.V.1996, fl., M.V. Ferrari 801 (MBM). Faxinal, 14.I.2012, fl., P.P.A. Ferreira et al. 833 (ICN). Imbaú, 14.I.2012, fl., P.P.A. Ferreira et al. 837 (ICN). Jaguariaíva, 16.XII.2010, fl., J.R.V. Iganci et al. 737 (ICN). Jundiaí do Sul, 3.V.1997, fl., J. Carneiro 323 (MBM). Lindoeste, 19.III.2011, fl., P.P.A. Ferreira \& J. Durigon 736 (ICN). Londrina, 30.IV.2004, fl., J. Carneiro et al. 35 (FUEL). Luiziana, 4.III.2006, fl., F.P. Borsato (HCF 3803). Ponta Grossa, XII.1969, fl., L. Krieger 7536 (SP). Reserva, 13.XII.1996, fl., V.F. Kinnup \& M.R.C. Paiva 84 (FUEL, ICN). Rolândia, 27.IV.1999, fl., D.A. Estevan et al. 51 (FUEL). Santa Teresa do Oeste, 19.III.2011, fl., P.P.A. Ferreira \& J. Durigon 739 (ICN). São Jerônimo da Serra, 13.V.2002, fl. e fr., K.L.V.R. de Sá et al. 116 (FUEL). Sapopema, 28.III.1998, fl., C. Medri et al. 599 (FUEL). Sengés, 29.VI.1910, fr., P. Dusén 9941 (NY, S). Tamarana, 23.IV.1999, fr., E.M. Francisco et al. (FUEL 28719). SANTA CATARINA: Botuverá, 30.III.2010, fl., A. Stival-Santos et al. 2207 (FURB). Itaió, 10.XII.1965, fl., R. Reitz \& M. Klein 17359 (HBR, NY, FLOR). Laguna, 3.IV.2010, fl., M. Verdi et al. 4640 (FLOR). Orleans, 16.IV.1991, fl., V.C. Zanette et al. 1033 
(CRI); 11.VI.1993, fr., V.C. Zanette \& C.M. Martinello 1851 (CRI). Vidal Ramos, 6.III.1958, fl., R. Reitz \& M. Klein 6593 (HBR, NY, S).

Distribui-se dos Estados Unidos à Argentina (O’Donell 1941), no Brasil só não possui registro nos estados do Piauí e Rio Grande do Sul (Simão-Bianchini \& Ferreira 2012). Ocorre na Floresta Ombrófila Mista, Floresta Estacional, Floresta Ombrófila Densa, Savana Tropical e Campos de Altitude Subtropicais, frequente em bordas de matas, mas também é encontrada em campos arbustivos, campos rupestres e em ambientes ruderais. Floresce e frutifica o ano todo, mais intensamente durante o verão.

Merremia macrocalyx é semelhante vegetativamente à $M$. dissecta e $M$. tuberosa, das quais difere por possuir folhas compostas.

7. Merremia tomentosa (Choisy) Hallier f., Bot. Jahrb. Syst. 16: 552. 1893. Ipomoea tomentosa Choisy, Convolv. Rar. 1: 133. 1837. Fig. 3a-f

Subarbusto ereto; ramos tomentosos, tricomas estrelados. Pecíolo tomentoso, 0,1-0,5 cm compr.; lâminas foliares tomentosas em ambas as faces, inteiras, elípticas, ovadas, oblongas ou oblanceoladas, 2-8 × 1-2,5 cm, base arredondada, margem lisa, ápice agudo ou obtuso. Inflorescência uniflora. Pedúnculo e pedicelo tomentosos, até 0,5 cm compr. e 0,5-1,5 cm compr., respectivamente. Bractéolas triangulares, tomentosas, 0,1-0,3 cm compr. Sépalas ovadas ou oblongas, externas pubescentes a glabras, 0,4-0,6 × 0,2-0,4 cm, ápice agudo ou obtuso, mucronado, internas glabras, 0,7-0,9 × 0,4-0,5 cm, ápice obtuso, com margem hialina. Corola infundibuliforme, branca, $2-2,5 \mathrm{~cm}$ compr., glabra. Estames 1-1,7 cm compr., filetes esparso-pubescentes. Ovário subgloboso, 4-locular, um rudimento seminal por lóculo; estilete 1,4-2 cm compr. Cápsula subglobosa, 4-valvar com 3-4 sementes pardas, 0,4-0,5 cm compr., vilosas. Material selecionado: PARANÁ: Paranaguá, 6.I.1987, fl. e fr., S.M. Silva 25163 (UEC); 9.I.1987, fr., S.M. Silva (UEC 85950).

Endêmica do Brasil, nos estados da Bahia, Minas Gerais, São Paulo, Goiás, Distrito Federal, Mato Grosso, Mato Grosso do Sul e Paraná (SimãoBianchini \& Ferreira 2012), nos demais estados ocorre na Savana Tropical, mas as coletas do Paraná são da Floresta Ombrófila Densa. Floresce e frutifica de setembro a abril.

Única espécie do gênero ocorrente no Brasil com hábito ereto e com folhas inteiras. Apenas $M$. digitata var. elongata possui indumento semelhante, tomentoso com tricomas estrelados, mas é prostrada com ápices volúveis.
8. Merremia tuberosa (L.) Rendle, Fl. Trop. Afr., 4: 104. 1905. Ipomoea tuberosa L., Sp. Pl. 1: 160. 1753.

Fig. $3 g$

Trepadeira; ramos glabros ou esparso-hirsutos, tricomas simples. Pecíolo glabro, 4-15(-20) cm compr.; lâminas foliares glabras, palmatissectas com 7 segmentos, contorno orbicular, 6-14 × 8-15 $\mathrm{cm}$, segmentos oblongos, elípticos ou lanceolados, inteiros, ápice acuminado. Dicásios com 1-7 flores. Pedúnculo e pedicelos glabros, 8-20 cm compr. e 1-4 cm compr., respectivamente. Brácteas e bractéolas lanceoladas, glabras, 0,2-0,6(-1) cm compr. Sépalas ovadas ou oblongas, glabras, ápice obtuso, mucronado, externas 2,3-3 × 1-1,5 cm, internas 2-2,5 $\times 0,8-1,3 \mathrm{~cm}$. Corola campanulado-infundibuliforme, amarela, 5-7,5 cm compr., glabra. Estames 1,5-2,4 cm compr., filetes denso-pubescentes. Ovário globoso, 4-locular, um rudimento seminal por lóculo; estilete 1,8-2,8 cm compr. Cápsula globosa, 4-valvar, cálice ampliado, com 1-4 sementes pretas, 2-2,5 cm compr., pubescentes.

Material selecionado: PARANÁ: Antonina, 3.IX.1997, fr., A. Soares \& W. Maschio 102 (MBM). Bela Vista do Paraíso, 25.IX.2000, fr., O.C. Pavão (FUEL 29953). SANTA CATARINA: Florianópolis, 19.V.1989, fl., D.B. Falkenberg 4812 (FUEL, FLOR).

Espécie cultivada como ornamental na Região Sul do Brasil, assim como em diversas partes do mundo, sendo difícil determinar sua área de origem. Floresce e frutifica o ano todo, mais intensamente durante o outono.

Merremia dissecta é a espécie mais próxima morfologicamente de $M$. tuberosa, mas difere por possuir flores brancas e sementes glabras, além do indumento que pode ser hirsuto. Merremia tuberosa é conhecida pelos nomes populares rosa-pau, rosade-pau, flor-de-madeira ou rosa-de-madeira que se referem aos frutos com as sépalas ampliadas, utilizados em artesanato (Lorenzi \& de Souza 1999).

9. Merremia umbellata (L.) Hallier f., Bot. Jahrb. Syst. 16: 552. 1893. Convolvulus umbellatus L., Sp. P1. 1: 155. 1753.

Fig. 3h-m

Trepadeira; ramos pubescentes, tricomas simples, glabrescentes. Pecíolo pubescente, 2-6 cm compr.; lâminas foliares pubescentes em ambas as faces, glabrescentes, inteiras, ovadas, 4-8(-10) $\times 2-5(-8) \mathrm{cm}$, base cordada ou hastada, margem lisa, ápice agudo ou obtuso, às vezes acuminado. Dicásios umbeliformes com 1-15 flores. Pedúnculo e pedicelos pubescentes, glabrescentes, 3-13 cm compr. e 0,8-3 cm compr., respectivamente. Brácteas e bractéolas triangulares, pubescentes, 

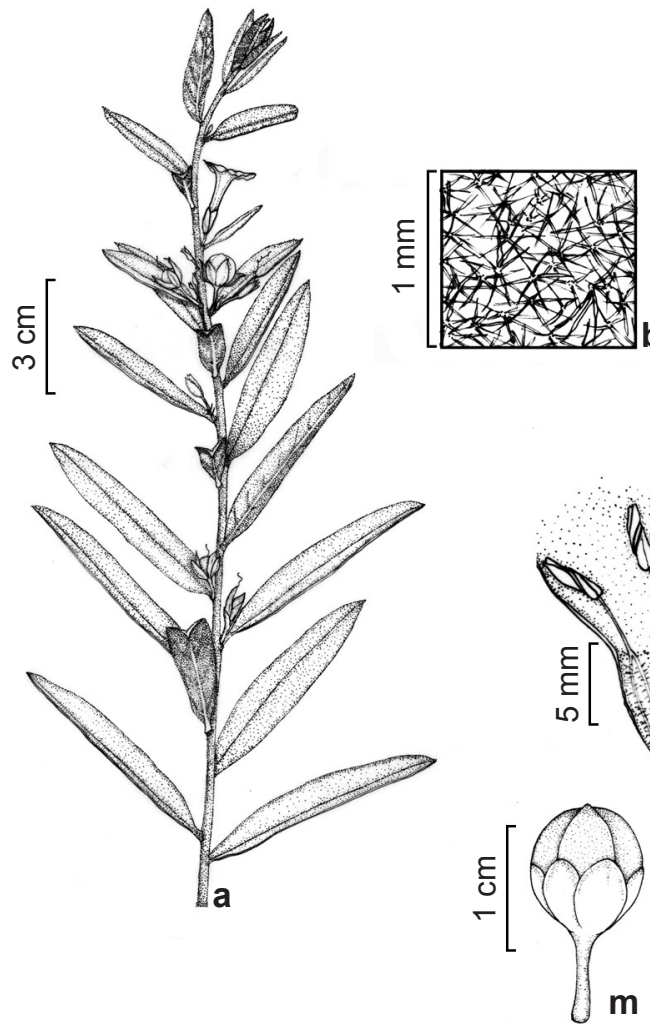
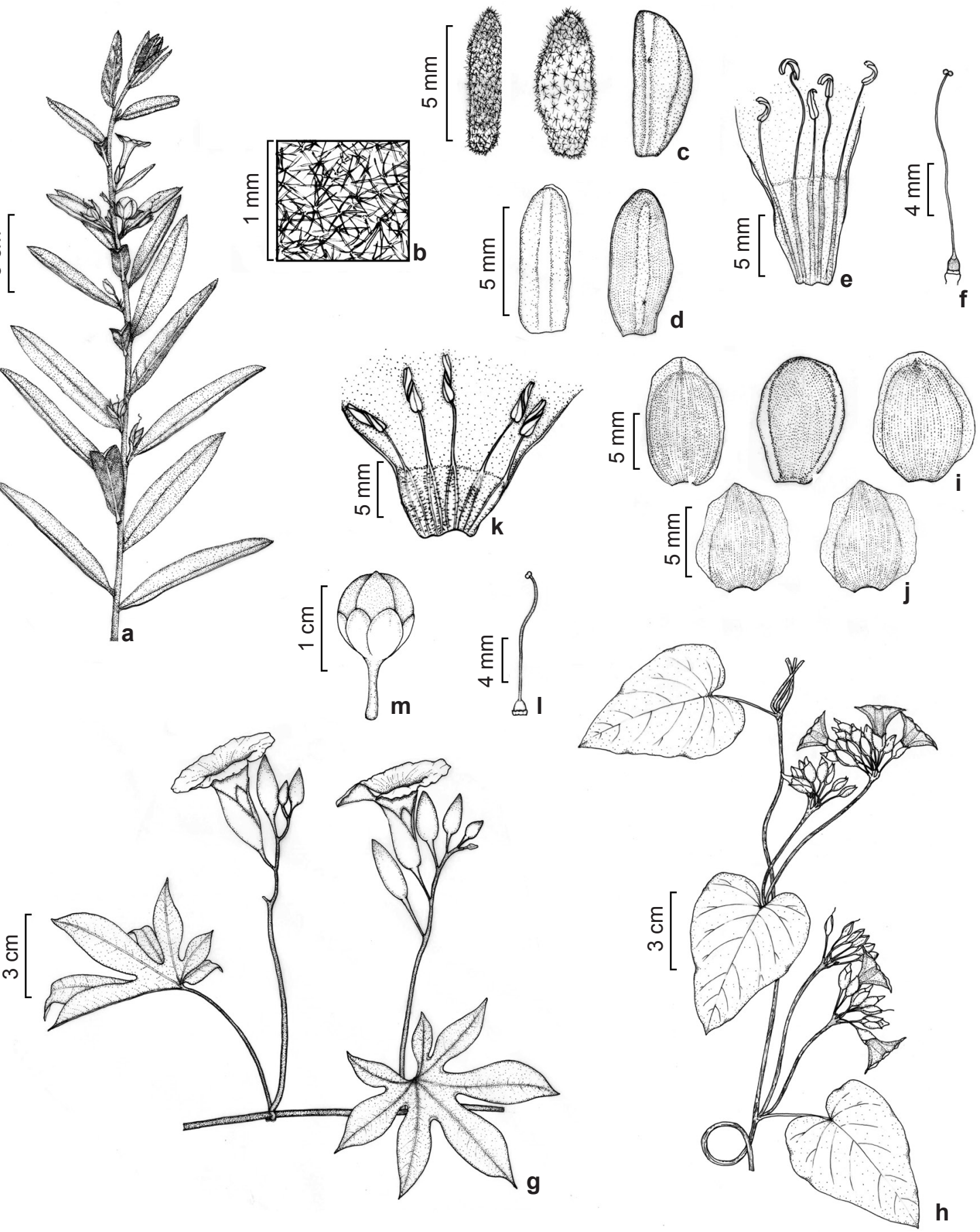

Figura 3 - a-f. Merremia tomentosa (Choisy) Hallier. - a. ramo. b. indumento da face abaxial da folha. c. sépalas externas. d. sépalas internas. e. corola aberta mostrando o androceu. f. gineceu (Silva 25163). G. Merremia tuberosa (L.) Rendle. - g. ramo (Falkenberg 4812). h-m. Merremia umbellata (L.) Hallier f. - h. ramo. i. sépalas externas. j. sépalas internas. k. corola aberta mostrando o androceu. 1. gineceu (Caxambu 766). m. fruto (Dometerco 3).

Figure 3 - a-f. Merremia tomentosa (Choisy) Hallier. - a. stem. b. trichomes on abaxial surface of leaf. c. outer sepals. d. inner sepals. e. corolla, opened to show androecium. f. gynoecium (Silva 25163). G. Merremia tuberosa (L.) Rendle. - g. stem (Falkenberg 4812). h-m. Merremia umbellata (L.) Hallier f. - h. stem. i. outer sepals. j. inner sepals. k. corolla, opened to show androecium. 1. gynoecium (Caxambu 766). m. fruit (Dometerco 3). 
0,1-0,2 cm compr. Sépalas obovadas, oblongas ou largo-elípticas, com margem hialina, ápice obtuso a subagudo, às vezes emarginado, mucronado, externas $0,8-1,1 \times 0,6-0,7 \mathrm{~cm}$, glabras ou esparsopubescentes, internas $0,6-0,9 \times 0,7-0,8 \mathrm{~cm}$, glabras. Corola campanulado-infundibuliforme, amarela, 1,8-2,5(-4) cm compr., áreas mesopétalas esparsoseríceas. Estames 1-1,3 cm compr., filetes esparsopubescentes. Ovário globoso, 2-locular com dois rudimentos seminais por lóculo; estilete 1,3-1,5 cm compr. Cápsula globosa, 4-valvar com 2-4 sementes pretas, 0,4-0,7 cm compr., pubescentes, tricomas mais longos nas margens.

Material selecionado: PARANÁ: Campo Mourão, 13.IV.2005, fl., M.G. Caxambu 766 (MBM, HCF); 15.VI.2005, fl., M.G. Caxambu 810 (HCF); 1.VII.2004, fl., O.A. Dometerco 3 (MBM, HCF). Fênix, 30.VI.2006, fl., O.S. Ribas \& J.M. Silva 7325 (MBM). Jataizinho, 14.IV.1999, fl., E.M. Francisco et al. (FUEL 29950). Jundiaí do Sul, 30.IV.2002, fl., J. Carneiro 1345 (MBM). Londrina, 16.VI.1988, fl., E.A. Silva et al. 114 (FUEL); 6.VI.1982, fl., E. Biomardi (FUEL 2526); 10.VI.1986, fl., H.M. Neto (FUEL 2865). São Carlos do Ivaí, 1.V.1966, fl. e fr., G. Hatschbach 14349 (MBM, HBR, NY, UPCB). 21.VIII.1991, fl., A.C. Cervi et al. 3277 (UPCB).

Distribui-se dos Estados Unidos à Argentina e nos Trópicos do Velho Mundo (Austin 1982b). No Brasil só não possui registro nos estados do Amapá, Espírito Santo, Santa Catarina e Rio Grande do Sul (Simão-Bianchini \& Ferreira 2012). Ocorre em bordas de Floresta Ombrófila Mista, de Floresta Estacional e em ambientes ruderais. Floresce e frutifica de abril a agosto.

Muito distinta de todas as outras espécies do gênero ocorrentes na Região Sul do Brasil e facilmente reconhecida por ser, entre estas, a única trepadeira com folhas inteiras, além das inflorescências umbeliformes. Dentre as espécies brasileiras, assemelha-se à Merremia wurdackii D.F.Austin \& Staples, ocorrente nas Regiões Norte e Centro-Oeste, que possui flores maiores, com duas bractéolas foliáceas na base.

\section{Agradecimentos}

À Dra. Rosangela Simão-Bianchini, Dra. Lilian Eggers e Dra. Lilian Auler Mentz, as valiosas observações e sugestões. Aos colegas Jaqueline Durigon e Márcio Verdi, todo auxílio prestado no campo e no laboratório. Ao ilustrador Edson Luís de Carvalho Soares, a confecção das pranchas. Aos curadores dos herbários nacionais e estrangeiros, o empréstimo, doação, envio de fotografias das exsicatas e/ou permissão para consulta das coleções.
À CAPES, a bolsa de Doutorado PROTAX concedida à primeira autora e ao CNPq, a Bolsa de Produtividade em Pesquisa concedida à segunda autora.

\section{Referências}

Austin, D.F. 1979. Studies of the Florida Convolvulaceae - II. Merremia. Florida Scientist 42:216-222.

Austin, D.F. 1982a. Convolvulaceae. Flora da Venezuela 8: $15-226$.

Austin, D.F. 1982b. Convolvulaceae. Flora of Ecuador 15: $1-98$.

Austin, D.F. 1998. Parallel and convergent evolution in the Convolvulaceae. In: Mathews, P. \& Sivadasan, M. (eds.). Diversity and taxonomy of tropical flowering plants. Mentor Books, Calicut. Pp. 201-234.

Austin, D.F. \& Staples G.W. 1983. Additions and changes in the neotropical Convolvulaceae - notes on Merremia, Operculina, and Turbina. Journal Arnold Arboretum 64: 483-489.

Demissew, S. 2001. A synopsis of the genus Merremia (Convolvulaceae) in the flora of Ethiopia and Eritrea. Kew Bulletin 56: 931-943.

Falcão J.I.A. 1954. Contribuição ao estudo das espécies brasileiras do gênero Merremia Dennst. Rodriguésia 16/17: 105-114.

Falcão, J.I.A. 1973. Contribuição ao estudo das Convolvulaceae no Rio Grande do Sul. Iheringia 17: 34-55.

Falcão, J.I.A. 1976. Contribuição ao estudo das Convolvuláceas de Santa Catarina. Sellowia 27: 3-24.

Ferguson, I.K.; Verdcourt, B. \& Poole, M.M. 1977. Pollen morphology in the genera Merremia and Operculina (Convolvulaceae) and its taxonomic significance. Kew Bulletin 31: 763-773.

Ferrer-Pereira, H.; Vivas-Arroyo, Y.; Hokche, O.; Nozawa, S.; Pérez-Cortéz, S.; Rodríguez, L.; Mostacero, J. \& Estrada-Sánchez, J. 2010. El género Merremia (Convolvulaceae) en Venezuela. Rodriguésia 61: 639-660.

Font Quer, P. 1979. Diccionario de botánica. Editorial Labor, Barcelona. 1244p.

Gonçalves, E.G. \& Lorenzi, H. 2011. Morfologia vegetal: organografia e dicionário ilustrado de morfologia das plantas vasculares. $2^{\mathrm{a}} \mathrm{ed}$. Instituto Plantarum, Nova Odessa. 544p.

Iganci, J.R.V; Heiden, G.; Miotto, S.T.S. \& Pennington, T. 2011. Campos de Cima da Serra: the Brazilian Subtropical Highland Grasslands show an unexpected level of plant endemism. Botanical Journal of the Linnean Society 167: 378-393.

Judd, W.S.; Campbell, C.S.; Kellogg, E.A.; Stevens, P.F. \& Donoghue, M.J. 2009. Sistemática vegetal: um enfoque filogenético. $3^{\mathrm{a}} \mathrm{ed}$. Artmed, Porto Alegre. $612 \mathrm{p}$.

Kissmann, K.G. \& Groth, D. 1992. Plantas infestantes e nocivas. t.2. BASF, São Paulo. Pp. 518-589. 
Leite, K.R.B.; Simão-Bianchini, R. \& Santos, F.A.R. 2005. Morfologia polínica de espécies do gênero Merremia Dennst. (Convolvulaceae) ocorrentes no estado da Bahia, Brasil. Acta Botanica Brasilica 19: 313-321.

Lorenzi, H. 1982. Plantas daninhas do Brasil: terrestres, aquáticas, parasitas, tóxicas e medicinais. Instituto Plantarum, Nova Odessa. Pp. 117-125.

Lorenzi, H. \& de Souza, H.M. 1999. Plantas ornamentais do Brasil: arbustivas, herbáceas e trepadeiras. $2^{\mathrm{a}}$ ed. Instituto Plantarum, Nova Odessa.

O’Donell, C.A. 1939. Las espécies argentinas del género Merremia. Lilloa 5: 35-64.

O’Donell, C.A. 1941. Revisión de las espécies americanas de Merremia. Lilloa 6: 467-554.

Payne, W.W. 1978. A glossary of plant hair terminology. Brittonia 30: 239-255

Radford, A.E.; Dickison, W.C.; Massey, J.R. \& Bell, C.R. 1974. Vascular plants systematics. Harper \& Row, New York. 891p.
Rambo, B. 1962. Convolvulaceae Riograndenses. Pesquisas: botânica 16: 6-30.

Rendle, A.B. 1905. Merremia. Flora of Tropical Africa 4: 101-114.

Simão-Bianchini, R. \& Ferreira, P.P.A. 2012. Merremia. In: Forzza, RC. et al. (eds.). Lista de espécies da flora do Brasil. Jardim Botânico do Rio de Janeiro. Disponível em <http://floradobrasil.jbrj.gov.br/2010/FB011518>. Acesso em 10 Fev 2012.

Stefanovic, S.; Krueger, L. \& Olmstead, R.G. 2002. Monophyly of the Convolvulaceae and circumscription of their major lineages based on DNA sequences of multiple chloroplast loci. American Journal of Botany 89: 1510-1522.

Stefanovic, S.; Austin, D.F. \& Olmstead, R.G. 2003. Classification of Convolvulaceae: a phylogenetic approach. Systematic Botany 28: 791-806.

Thiers, B. (continuamente atualizado). 2012. Index Herbariorum. Disponível em $<$ http://sweetgum.nybg. org/ih/>. Acesso em 10 Fev 2012. 